\title{
Does Hukou origin affect establishment of health records in migrant inflow communities? A nation-wide empirical study in China
}

\author{
Yangyang Qian', Dandan Ge' ${ }^{1}$ Li Zhang ${ }^{1}$, Long Sun ${ }^{1}$, Jiajia Li ${ }^{1}$ and Chengchao Zhou ${ }^{2 *}$ (D
}

\begin{abstract}
Background: With the implementation of Chinese economic reform and rapid urbanization, policies and values surrounding migration have changed and given rise to unprecedented population mobility. This study is designed to examine the effect of Hukou origin on establishment of health records among internal migrants in China.

Methods: The data used for this study are from the 2015 National Internal Migrant Population Dynamic Monitoring Survey, covering 112,782 migrants nationwide. For continuous variables, the $p$ value is calculated using Student $t$ test; for categorical variables, the $\mathrm{p}$ value is calculated using chi-square test. Binary logistic regression with an enter method is employed to assess the association of establishment of health records with origin residence.

Results: About 35.1\% of the migrant population has established health records in their inflow communities, with $37.4 \%$ established among those of urban origin and $34.8 \%$ established among those of rural origin. The establishment of health records is significantly higher among migrants of urban origin than among migrants of rural origin $(\mathrm{OR}=1.057 ; 1.017-1.098)$. Our results also show that among populations of both rural and urban origin, inter-province migrants, along with migrants who are employers, have no plans for long-term residence, have no insurance, and have more family income less likely to establish health records.

Conclusions: This study demonstrates that residence is associated with establishment of health records among the migrant population in China. Targeted policies should be made to improve the establishment of health records among migrants of both rural and urban origins.
\end{abstract}

Keywords: Hukou, Health records, Internal migrants, Determinants

\section{Background}

Before the 1980s, migration was not very common within China due to institutional restrictions, undeveloped transportation, and cultural traditions of attachment to one's native land [1]. However, with the implementation of Chinese economic reform and rapid urbanization, policies and values surrounding migration have changed and given rise to unprecedented population mobility. It is estimated that the internal migrant population reached 245 million in China at the end of 2016 [2]. However, compared with permanent

\footnotetext{
* Correspondence: zhouchengchao@sdu.edu.cn

${ }^{2}$ School of Public Health, Key Lab of Health Economics and Policy Research, Shandong University, 44 Wen-hua-xi Road, Jinan 250012, Shandong, China Full list of author information is available at the end of the article
}

residents, migrants are worse off in terms of accessibility to public health services. Migrant populations have poorer maternal health care, higher rates of infectious diseases, and poorer management of childhood immunization [3]. In 2014, the Chinese central government issued a regulation which indicated that 11 basic public health services should be fully and freely provided to migrants to improve health care utilization, including the establishment of health records [4]. The responsibility of establishing health records for the migrant population has largely fallen to community health centers. They can help health providers and patients to make appropriate decisions for health management or treatment. Recently, health records have also been used to

(c) The Author(s). 2018 Open Access This article is distributed under the terms of the Creative Commons Attribution 4.0 International License (http://creativecommons.org/licenses/by/4.0/), which permits unrestricted use, distribution, and 
facilitate the management of chronic diseases. It is a constituent part of community health service [5].

Health records are important health information management tools that enable individuals to store, retrieve, and manage their personal health information and ultimately, to make decisions related to their health $[6,7]$. Health records include basic personal information, health examination information, health management records, and other records of medical and health services [8]. The primary beneficiaries of health records are individuals with chronic diseases, and those who are elderly and disabled [9]. Health records are helpful for supporting, prevention, and early detection of chronic diseases. Patients can use health records to improve their health and effectively manage their diseases. In addition, health records can also help caregivers to maintain an ongoing connection with patients in order to offer more customized health services.

Hukou is the household registration system in China, designed in the 1950s to restrict internal population migration, and especially rural-to-urban migration. A Hukou record officially identifies a person as a resident of a particular place. Residents of China are mainly categorized into two types, rural Hukou (also called agricultural Hukou) and urban Hukou (also called non-agricultural Hukou). The Hukou system is an important institution for regulating population migration. Since the 1980 s, more and more Chinese citizens live and work illegally outside their officially registered areas (called "non-Hukou migrants") and as a result have far less eligibility to public services. In the 1990s, a reform started to relax the system to allow some residents to legally migrate to new places with the official authorization of a temporary residency permit. Thus, in the past two decades a new subgroup, Hukou migrants, has emerged in China. Even though Hukou migrants are authorized by the government to live or work legally within a new place, they face similar barriers to non-Hukou migrant when it comes to accessing public services. Their eligibility for most welfare benefits (e.g., health care, education, labor, housing, and social subsidies) remains poorer in local communities than that of permanent residents. Thus, some researchers have suggested that internal migrants should be distinguished by their origins of place, not their authorization status. That is to say, Hukou origin may be an important status marker among migrants that deserves more attention by scholars.

Many previous studies have explored factors associated with use intentions of personal health records. Factors associated with use intentions of personal health records included patient satisfaction with the provider, interactions between environmental factors, and personal tendency $[10,11]$. Researchers also have identified factors associated with adoption of health records from the perspective of both health care providers and patients. From caregivers' perspective, factors associated with adoption of health records included practicing in a medically underserved location, geographic health professional shortage areas, being an international medical graduate, privacy concerns, and social influence $[12,13]$. From patients' perspective, influencing factors related to establishment of health records were counties and townships of residence, satisfaction about health education, age, education, housing status, monthly income, and self-reported health $[14,15]$. However, most of the existing studies only focus on health care providers or the general population. To date, few studies have focused the establishment of health records among internal migrants in China, and no studies have explored the disparity in establishing health records between migrants with different Hukou origin.

To fill this gap, our study aims to explore the effect of Hukou origin on the establishment of health records for internal migrants in China. To do so, we have the following specific objectives. First, we will explore the establishment of health records in inflow communities among the migrant population of China. Second, we will look for differences in the establishment of health records between migrants with different Hukou origin. Third, we will identify the factors associated with establishment of health records among migrants of rural and urban origin respectively.

\section{Methods}

Data

The data used for this study are from the 2015 National Internal Migrant Population Dynamic Monitoring Survey (NIMPDMS), conducted by the National Health and Family Planning Commission of China. The overall goal of the survey was to understand accessibility for migrants of public health and family planning services. It was a cross-sectional, nationally representative survey of internal migrants aged $15+$ who had been living in the sample cities for more than one month in 2015. The study was conducted in 31 provinces, municipalities, and autonomous regions, and migrant gathering areas in Xinjiang Production and Construction Corps.

The participants of this study were selected by using a stratified multi-stage sampling method with a probability-proportional-to-size (PPS) approach [16]. Face-to-face interviews were conducted by the interviewers who were trained by local health bureau staff. In total, 112,782 migrants with rural or urban origin were included in the analysis.

\section{Variables and measures Dependent variable}

The dependent variable is establishment of health records, which is evaluated based on interviewees' answers to 'Do you have established health records in your local 
community?' If the response was 'no, I have never heard of this' or 'no, but I have heard of this', the establishment of health records was coded as 'no.' On the contrary, if the answer was 'I have established health records, the establishment of health records was categorized as 'yes.'

\section{Independent variables}

Hukou origin is distinguished by migrants' original place of residence. Participants from urban areas were coded as "urban origin", and participants from rural areas were coded as "rural origin."

Demographic characteristics were also used, including age, gender (male vs. female), marital status (single vs. married), and ethnic group (Han vs. ethnic minority).

Socio-economic characteristics used include education (middle school or below vs. high school or above), number of children ( $<2$ vs. $\geq 2$ ), employment status (employee, employer, self-supporting laborers, and others), and household income (Q1, Q2, Q3 and Q4, Quartile 1 (Q1) is the poorest and Quartile 4 (Q4) is the richest).

Migration characteristics used include mobility area (inter-provincial vs. intra-provincial), length of migration ( $\leq 1$ year vs. $>1$ years), and plans for long-term residence of more than 5 years (yes, no, and not decided yet).

\section{Statistical analysis}

Statistical analyses were performed using SPSS 21.0. For continuous variables, the $p$ value was calculated using Student's $t$ test; for categorical variables, the $\mathrm{p}$ value was calculated using the chi-square test. Binary logistic regression with an enter method was employed to assess the association of establishment of health records with residence. All reported CIs were calculated at the 95\% level. Statistical significance was set at the 5\% level. Sampling weights were included in all analyses to adjust for the complex survey design.

\section{Limitations}

There are several limitations to this paper. First, information about the establishment of health records and household income was self-reported, thus leading to the possibility of subjective bias. Second, although we are able to identify the association between Hukou origin and establishment of health records in migrants, we are unable to identify the exact cause of the observed association. Third, the study sample is specific to China, thus the results from this study are not necessarily generalizable to other contexts.

\section{Results}

Table 1 shows basic information about the 112,782 migrants in our sample. About $35.1 \%$ of the migrant population have established health records in their local communities, and the percentage is $37.4 \%$ among those of urban origin and $34.8 \%$ among those of rural origin. The average age of the migrant population is 37.23 , with a standard deviation of 8.38 . Generally speaking, the majority the migrants in our sample population are male (58.6\%), Han (93.1\%), with an education level of middle school or below (69.3\%), married (97.2\%), are inter-provincial migrants (51.2\%), have lived for over 1 year in their current residence (74.3\%), have plans for long-term residence (63.2\%), have less than 2 children (59.5\%), have work status of "employee" (50.7\%), have insurance (94.0\%), and are in Quartile 2 of the income distribution (35.8\%).

We present our results in two models so that we can better understand the effect of Hukou origin on establishment of health records among migrants in China (see Table 2). Model 1 shows that establishment of health records is significantly higher in migrants with urban origin than in migrants with rural origin $(\mathrm{OR}=$ 1.120; 95CI 1.082-1.160). Even after controlling for all other variables, establishment of health records is still significantly higher in migrants with urban origin than in migrants with rural origin ( $\mathrm{OR}=1.057 ; 1.017-1.098)$.

Univariate analysis indicates that migrants of rural origin are more likely to have established health records if they are female $(P=0.000)$, have education levels of high school or above $(P=0.000)$, are inter-province migrants $(P=0.000)$, have lived in their current residence for more than 1 year $(P=0.000)$, have work status of "employer" $(P=0.000)$, and are self-supporting laborers $(P=0.000)$. Migrants of rural origin are less likely to have established health records if they have no plans of long-term residence $(P=0.000)$ or haven't decided yet $(P=0.000)$, have 2 or more children $(P=0.000)$, have no insurance $(P=0.000)$, and have higher family monthly income in the last 4 years $(P=0.000)$. As for migrants with urban origin, the univariate analysis shows that they are more likely to have established health records if they are older $(P=0.021)$, are inter-province migrants $(P=0.000)$, and are self-supporting laborers $(P=0.004)$. Migrants with urban origin are less likely to have established health records if they are ethnic minorities $(P=0.049)$, have education levels of high school or above $(P=0.026)$, have no plans for long-term residence $(P=0.000)$, have no insurance $(P=0.000)$, and are in the richest quartile (see Additional file 1: Table S1).

Table 3 presents the results of a multi-logistic analysis of factors associated with establishing health records in migrants with rural and urban origin. Factors found to be associated with the establishment of health records for migrants with rural origin during univariate analysis were all identified as determinants in the multivariate analysis as well. For migrants with urban origin, the multi-logistic regression indicates that migrants who are inter-province migrants $(P=0.000)$, and who are employers $(P=0.048)$ are more likely to have established 
Table 1 Socio-demographic characteristics of migrant population in China $(n=112,782)$

\begin{tabular}{|c|c|c|c|c|c|}
\hline Characteristics & $\begin{array}{l}\text { Total } \\
\text { n (\%) }\end{array}$ & $\begin{array}{l}\text { Rural } \\
\text { n (\%) }\end{array}$ & $\begin{array}{l}\text { Urban } \\
\mathrm{n}(\%)\end{array}$ & $x^{2} / t$ & $P$ \\
\hline $\mathrm{N}$ & $112,782(100.0)$ & $99,650(85.7)$ & $16,132(14.3)$ & & \\
\hline Health records & & & & 41.689 & 0.000 \\
\hline Yes & $39,637(35.1)$ & $33,605(34.8)$ & 6032(37.4) & & \\
\hline No & $73,145(64.9)$ & $63,045(65.2)$ & $10,100(62.6)$ & & \\
\hline Age & $37.23(8.38)$ & $37.18(8.42)$ & $37.51(8.12)$ & 6.458 & 0.000 \\
\hline Gender & & & & 1.412 & 0.237 \\
\hline Male & $66,110(58.6)$ & $56,585(58.5)$ & $9525(59.0)$ & & \\
\hline Female & $46,672(41.4)$ & $40,065(41.5)$ & $6607(41.0)$ & & \\
\hline Ethnic group & & & & 31.395 & 0.000 \\
\hline Han & $104,986(93.1)$ & $89,802(92.9)$ & $15,184(94.1)$ & & \\
\hline Ethnic minority & $7796(6.9)$ & $6848(7.1)$ & $948(5.9)$ & & \\
\hline Education & & & & $13,781.375$ & 0.000 \\
\hline Middle school or below & $78,210(69.3)$ & 73,387(75.9) & 4823(29.9) & & \\
\hline High school or above & $34,572(30.7)$ & $23,263(24.1)$ & $11,309(70.1)$ & & \\
\hline Marital status & & & & 246.362 & 0.000 \\
\hline Single ${ }^{a}$ & $3115(2.8)$ & $2367(2.4)$ & $748(4.6)$ & & \\
\hline Married ${ }^{b}$ & $109,667(97.2)$ & $94,283(97.6)$ & $15,384(95.4)$ & & \\
\hline Movement area & & & & 58.584 & 0.000 \\
\hline Inter-provincial & $57,768(51.2)$ & $49,875(51.6)$ & $7893(48.9)$ & & \\
\hline Intra-provincial & $55,014(48.8)$ & $49,775(48.4)$ & 8239(51.1) & & \\
\hline Time in inflow area & & & & 14.918 & 0.000 \\
\hline$\leq 1$ & $29,038(25.7)$ & $25,308(26.2)$ & $3730(23.1)$ & & \\
\hline$>1$ & $83,744(74.3)$ & $71,342(73.8)$ & $12,402(76.9)$ & & \\
\hline Plans for long-term residence ( $>5$ years) & & & & 524.115 & 0.000 \\
\hline Yes & $71,237(63.2)$ & $59,758(61.8)$ & $11,479(71.2)$ & & \\
\hline No & $12,748(11.3)$ & $11,232(11.6)$ & $1516(9.4)$ & & \\
\hline Not decided yet & $28,797(25.5)$ & $25,660(26.5)$ & $3137(19.4)$ & & \\
\hline Number of children & & & & 4124.906 & 0.000 \\
\hline$<2$ & $67,063(59.5)$ & $53,763(55.6)$ & $13,300(82.4)$ & & \\
\hline$\geq 2$ & $45,719(40.5)$ & $42,887(44.4)$ & $2832(17.6)$ & & \\
\hline Employment status & & & & 1590.730 & 0.000 \\
\hline Employee & $57,142(50.7)$ & $47,098(48.7)$ & $10,044(62.3)$ & & \\
\hline Employer & $9850(8.7)$ & $8207(8.5)$ & 1643(10.2) & & \\
\hline Self-supporting laborers & $44,046(39.1)$ & $40,000(41.4)$ & $4046(25.1)$ & & \\
\hline Others & $1744(1.5)$ & $1345(1.4)$ & $399(2.5)$ & & \\
\hline Health insurance & & & & 428.804 & 0.000 \\
\hline Yes & $106,065(94.0)$ & $91,470(94.6)$ & $14,595(90.5)$ & & \\
\hline No & $6717(6.0)$ & $5180(5.4)$ & $1537(9.5)$ & & \\
\hline Family monthly income in the last year ${ }^{c}$ & & & & 1874.309 & 0.000 \\
\hline Q1 & $28,485(25.3)$ & $25,439(26.3)$ & $3046(18.9)$ & & \\
\hline Q2 & $40,403(35.8)$ & $35,524(36.8)$ & 4879(30.2) & & \\
\hline Q3 & $22,641(20.1)$ & $19,389(20.1)$ & $3252(20.2)$ & & \\
\hline Q4 & $21,253(18.8)$ & $16,298(16.9)$ & $4955(30.7)$ & & \\
\hline
\end{tabular}

Age is presented as Mean(Standare deviation); The $P$-values in boldface mean statistical significance ${ }^{\text {a }}$ Single includes those who are divorced $(2.3 \%)$ and widowed $(0.5 \%)$

${ }^{\mathrm{b}}$ Married includes those who are first married (95.5\%) and remarried (1.7\%)

'Quartile 1 (Q1) is the poorest and Quartile $4(\mathrm{Q} 4)$ is the richest 
Table 2 Association of residence and health records in migrant population in China

\begin{tabular}{|c|c|c|c|c|}
\hline \multirow[t]{2}{*}{ Characteristics } & \multicolumn{2}{|c|}{ Model 1 (No covariates) } & \multicolumn{2}{|l|}{ Model 2 (Covariates) } \\
\hline & $\mathrm{OR}(95 \% \mathrm{Cl})$ & $P$ & OR $(95 \% \mathrm{Cl})$ & $P$ \\
\hline \multicolumn{5}{|l|}{ Hukou } \\
\hline Rural & 1.0 & & 1.0 & \\
\hline Urban & $1.120(1.082-1.160)$ & 0.000 & $1.057(1.017-1.098)$ & 0.005 \\
\hline Age & & & $1.002(1.001-1.004)$ & 0.007 \\
\hline \multicolumn{5}{|l|}{ Gender } \\
\hline Male & & & 1.0 & \\
\hline Female & & & $1.097(1.070-1.126)$ & 0.000 \\
\hline \multicolumn{5}{|l|}{ Ethnic group } \\
\hline Han & & & 1.0 & \\
\hline $\begin{array}{l}\text { Ethnic } \\
\text { minority }\end{array}$ & & & $0.956(0.910-1.005)$ & 0.077 \\
\hline \multicolumn{5}{|l|}{ Education } \\
\hline $\begin{array}{l}\text { Middle school } \\
\text { or below }\end{array}$ & & & 1.0 & \\
\hline $\begin{array}{l}\text { High school or } \\
\text { above }\end{array}$ & & & $1.111(1.077-1.145)$ & 0.000 \\
\hline \multicolumn{5}{|l|}{ Marital status } \\
\hline Single ${ }^{a}$ & & & 1.0 & \\
\hline Married $^{b}$ & & & 1.024(0.947-1.106) & 0.552 \\
\hline \multicolumn{5}{|l|}{ Movement area } \\
\hline Inter-provincial & & & 1.0 & \\
\hline Intra-provincial & & & $1.882(1.828-1.937)$ & 0.000 \\
\hline \multicolumn{5}{|l|}{ Time in inflow area } \\
\hline$\leq 1$ & & & 1.0 & \\
\hline$>1$ & & & $1.206(1.170-1.242)$ & 0.000 \\
\hline \multicolumn{5}{|c|}{ Plans for long-term residence ( $>5$ years) } \\
\hline Yes & & & 1.0 & \\
\hline No & & & $0.646(0.618-0.674)$ & 0.000 \\
\hline $\begin{array}{l}\text { Not decided } \\
\text { yet }\end{array}$ & & & $0.833(0.808-0.858)$ & 0.000 \\
\hline \multicolumn{5}{|l|}{ Number of children } \\
\hline$<2$ & & & 1.0 & \\
\hline$\geq 2$ & & & $0.917(0.892-0.943)$ & 0.000 \\
\hline \multicolumn{5}{|l|}{ Employment status } \\
\hline Employee & & & 1.0 & \\
\hline Employer & & & $1.143(1.091-1.197)$ & 0.000 \\
\hline $\begin{array}{l}\text { Self- } \\
\text { supporting } \\
\text { laborers }\end{array}$ & & & $1.146(1.115-1.177)$ & 0.000 \\
\hline Others & & & $0.967(0.873-1.072)$ & 0.523 \\
\hline \multicolumn{5}{|l|}{ Health insurance } \\
\hline Yes & & & 1.0 & \\
\hline No & & & $0.784(0.742-0.829)$ & 0.000 \\
\hline
\end{tabular}

Table 2 Association of residence and health records in migrant population in China (Continued)

\begin{tabular}{|c|c|c|c|c|}
\hline \multirow[t]{2}{*}{ Characteristics } & \multicolumn{2}{|c|}{ Model 1 (No covariates) } & \multicolumn{2}{|l|}{ Model 2 (Covariates) } \\
\hline & OR $(95 \% \mathrm{Cl})$ & $P$ & $\mathrm{OR}(95 \% \mathrm{Cl})$ & $P$ \\
\hline \multicolumn{5}{|c|}{ Family monthly income in the last year ${ }^{c}$} \\
\hline Q1 & & & 1.0 & \\
\hline Q2 & & & $0.969(0.938-1.001)$ & 0.059 \\
\hline Q3 & & & $0.909(0.875-0.945)$ & 0.000 \\
\hline Q4 & & & $0.849(0.815-0.884)$ & 0.000 \\
\hline Constant & 0.533 & 0.000 & 0.327 & 0.000 \\
\hline R squared & & 0.001 & & 0.049 \\
\hline Observations & 112,782 & & & \\
\hline
\end{tabular}

${ }^{a}$ Single includes those who are divorced (2.3\%) and widowed (0.5\%); The $P$ values in boldface mean statistical significance

${ }^{\mathrm{b}}$ Married includes those who are first married (95.5\%) and remarried (1.7\%)

c Quartile 1 (Q1) is the poorest and Quartile 4 (Q4) is the richest

health records. Those who are ethnic minorities $(P=0.002)$, who have no plans for long-term residence $(P=0.000)$, who have no insurance $(P=0.000)$, and who are in the richest quartile $(P=0.000)$ are less likely to have established health records.

\section{Discussion}

Our study finds that $35.1 \%$ of the migrant population has established health records in their local communities, which is higher than past research has found. A 2013 study showed that $16.9 \%$ of China's migrant population had established health records [17]. Two 2014 studies in Sichuan province and Shanghai found that $25.2 \%$ and $18.9 \%$ of the migrant populations had established health records, respectively $[18,19]$. In the past five years, the Chinese government has taken several measures to promote equal access to basic public health services among residents, including migrants, and progress resulting from these measures can already be seen. However, there is still a long way to go in this respect, and policymakers must continue to develop targeted interventions to improve the utilization of essential public health services among migrants.

The current study indicates that migrants of urban origin are more likely to have established health records than those of rural origin, which demonstrates that Hukou origin is associated with establishment of health records among migrants. This finding is supported by a study by Jiang et al., which also found that migrants with urban origin are more likely to have established health records than their counterparts of rural origin [20]. This can likely be explained by the fact that compared with migrants of urban origin, migrants of rural origin are more marginalized in many ways. One study shows strong evidence of marginalization experienced by migrant employees of rural origin, including lower employment and working 
Table 3 Multivariate analysis of factors associated with establishing health records in rural and urban migrant population in China, 2015

\begin{tabular}{|c|c|c|c|c|}
\hline \multirow[t]{2}{*}{ Characteristics } & \multicolumn{2}{|l|}{ Rural migrants } & \multicolumn{2}{|l|}{ Urban migrants } \\
\hline & OR a $(95 \% \mathrm{Cl})$ & $P$ & OR a $(95 \% \mathrm{Cl})$ & $P$ \\
\hline$\overline{\text { Age }}$ & NA & & $1.002(0.998-1.006)$ & 0.357 \\
\hline Gender & & & NA & \\
\hline Male & 1.0 & & & \\
\hline Female & $1.100(1.070-1.131)$ & 0.000 & & \\
\hline Ethnic group & NA & & & \\
\hline Han & & & 1.0 & \\
\hline Ethnic minority & & & $0.797(0.692-0.917)$ & 0.002 \\
\hline \multicolumn{5}{|l|}{ Education } \\
\hline Middle school or below & 1.0 & & 1.0 & \\
\hline High school or above & $1.128(1.092-1.165)$ & 0.000 & $0.982(0.910-1.060)$ & 0.641 \\
\hline \multicolumn{5}{|l|}{ Movement area } \\
\hline Inter-provincial & 1.0 & & 1.0 & \\
\hline Intra-provincial & $1.900(1.842-1.960)$ & 0.000 & $1.710(1.585-1.846)$ & 0.000 \\
\hline Time in inflow area & & & NA & \\
\hline$\leq 1$ & 1.0 & & & \\
\hline$>1$ & $1.243(1.204-1.284)$ & 0.000 & & \\
\hline \multicolumn{5}{|c|}{ Plans for long-term residence ( $>5$ years) } \\
\hline Yes & 1.0 & & 1.0 & \\
\hline No & $0.643(0.613-0.673)$ & 0.000 & $0.663(0.589-0.746)$ & 0.000 \\
\hline Not decided yet & $0.809(0.783-0.836)$ & 0.000 & 1.009(0.928-1.097) & 0.829 \\
\hline Number of children & & & NA & \\
\hline$<2$ & 1.0 & & & \\
\hline$\geq 2$ & $0.922(0.896-0.948)$ & 0.000 & & \\
\hline \multicolumn{5}{|l|}{ Employment status } \\
\hline Employee & 1.0 & & 1.0 & \\
\hline Employer & $1.138(1.081-1.197)$ & 0.000 & $1.119(1.001-1.251)$ & 0.048 \\
\hline Self-supporting laborers & $1.149(1.116-1.183)$ & 0.000 & 1.076(0.994-1.165) & 0.071 \\
\hline Others & $0.971(0.863-1.093)$ & 0.631 & 0.993(0.806-1.222) & 0.944 \\
\hline \multicolumn{5}{|l|}{ Health insurance } \\
\hline Yes & 1.0 & & 1.0 & \\
\hline No & $0.783(0.735-0.834)$ & 0.000 & $0.786(0.701-0.881)$ & 0.000 \\
\hline \multicolumn{5}{|c|}{ Household monthly income in the last year ${ }^{a}$} \\
\hline Q1 & 1.0 & & 1.0 & \\
\hline Q2 & $0.961(0.928-0.994)$ & 0.022 & $1.025(0.932-1.126)$ & 0.612 \\
\hline Q3 & $0.894(0.858-0.931)$ & 0.000 & $1.000(0.901-1.111)$ & 0.997 \\
\hline Q4 & $0.860(0.823-0.898)$ & 0.000 & $0.830(0.749-0.920)$ & 0.000 \\
\hline
\end{tabular}

$\mathrm{OR}_{\mathrm{a}}$ : adjusted odds ratio; NA: Not applicable; The $P$-values in boldface mean statistical significance

${ }^{a}$ Quartile $1(\mathrm{Q} 1)$ is the poorest and Quartile $4(\mathrm{Q} 4)$ is the richest

conditions, lack of access to social security and medical benefits, difficulties in providing education to children, and barriers to housing [21]. In contrast, migrants of urban origin are more adaptive to local urban communities, which makes them more proactive about using public services, including medical services and health records.

We also found that intra-provincial migrant status, employer status, plans for long-term residence, possession of insurance, and lower household income are predictors for 
establishment of health records among migrants of both rural and urban origins. Intra-provincial migrants are also more likely to establish health records in their inflow communities. When migrants' place of origin is closer to their new residence, lifestyle and health-related policy tend to be more similar between the two locations. Thus, these migrants are more able and willing to establish health records in their communities. We also find that migrants with work status as employers are more likely to establish health records. A study in the US finds that many employers provide sponsored personal health records for their employees, which indicates that employers might be more aware about the importance of establishing health records [22].

Migrants with no plans for long-term residence are also less likely to establish health records in local communities. Those who do not plan to reside long-term in their inflow areas may not have stable work and as a result may be less willing to establish health records. Migrants without insurance are also less likely to establish health records. Health records have been identified as an important tool for people to manage their own health, improve patient-physician communication [23], and facilitate continuity of care [24]. Those who have no health insurance might have low awareness of their own health and may not know the benefits of health records which could be the reason why they do not establish health records. Interestingly, higher household income is found to be negatively associated with establishment of health records among the migrants, which is inconsistent with previous studies [19]. Those migrants who have higher income might have more stressful work, and thus have less time to make use of public health services [25].

Among migrants of rural origin, we find that women are more likely to establish health records than men, which is consistent with previous studies [26]. We also find that those with education levels of high school or above tend to establish health records. This could be the effect of higher education on health consciousness or the indirect effect of education on employment characteristics. Migrants who have lived in their local area for more than one year are more likely to establish health records. The longer they stay in one place, the more familiar they are with that place. A longer stay also means stability which contributes to the establishment of health records. A study by Jiang et al. finds that the number of children is not associated with establishment of health records [20]. In contrast, our research shows that those who have two or more children are less likely to establish health records.

Among migrants of urban origin, ethnic minority migrants are less likely to establish health records than Han migrants. One possible explanation for this finding might be that the awareness of preventive health services is important in determining the establishment of health records in local communities.
Some previous studies indicate that awareness of public health services is poorer among ethnic minority people than among Han people, and such awareness will inevitably affect whether they establish health records in inflow communities [27, 28]. Another explanation might be that the average education level of Hans is slightly higher than that of other ethnicities, which has been demonstrated in previous studies, and it is also true in this study. This may explain, to some extent, why ethnic minority urban migrants are less likely to establish health records. It is important to develop targeted interventions to promote basic public health services among ethnic minority migrants.

\section{Conclusion}

Our study suggests that origin residence is associated with establishment of health records among migrant population in China, and specific interventions should be developed to improve essential public health services use among migrants of rural origin. This study also implies a need for more diverse health education for the migrant population. The government should also give more financial support to provide public health services such as continuous health records management for migrant populations. Furthermore, we identified some risk factors for establishment of health records among the migrant population of rural and urban origin separately. Policies should be designed to target the needs of these different subgroups.

\section{Additional file}

Additional file 1: Table S1. Univariate analysis of factors associated with establishing health records in rural and urban migrant population in China, 2015. We presented univariate analysis of different factors associated with establishing health records in rural and urban migrant population respectively in this table. (DOCX $22 \mathrm{~kb}$ )

\section{Acknowledgements}

We thank the officials of local health agencies and all participants and staff at the study sites for their cooperation. We also thank Ms. Emma Auden from Stanford University to help to polish the manuscript.

\section{Funding}

We are grateful for funding support from the National Science Foundation of China (71003067, 71473152 and 71774104), Chinese Medical Board (CMB-16-257), Cheeloo Youth Scholar Grant, and Shandong University (IFYT1810, 2012DX006).

\section{Availability of data and materials}

The data used in this study are from the National Health and Family Planning Commission of China (NHFPCC). The authors cannot share the data without approval from the NHFPCC. Those who want to request the data are encouraged to contact the corresponding author of this paper.

\section{Authors' contributions}

$C Z$ and $Y Q$ conceived the idea. $C Z, Y Q, D G, L S, J L$, and $L Z$ participated in the statistical analysis and interpretation of the results. YQ drafted the manuscript. LS and JL gave many valuable comments on the draft and also polished it. All authors read and approved the final manuscript. 
Ethics approval and consent to participate

Not applicable.

\section{Consent for publication}

Not applicable.

\section{Competing interests}

The authors declare that they have no competing interests.

\section{Publisher's Note}

Springer Nature remains neutral with regard to jurisdictional claims in published maps and institutional affiliations.

\section{Author details}

'School of Public Health, Shandong University, Jinan 250012, China. ${ }^{2}$ School of Public Health, Key Lab of Health Economics and Policy Research, Shandong University, 44 Wen-hua-xi Road, Jinan 250012, Shandong, China.

Received: 14 January 2018 Accepted: 2 September 2018

\section{Published online: 10 September 2018}

\section{References}

1. Yang J. From isolation and choice of merging to integration: the theory of migrant population integration problems (in Chinese). Population Research. 2009:33(1):17-29.

2. National Bureau of Statistics of China. 2017. Available at: http://www.stats. gov.cn/tjsj/zxfb/201702/t20170228_1467424.html. (Accessed 4 Aug 2018).

3. Xiao Y. Public health management analysis of migrant population (in Chinese). China Health Industry. 2017;14(5):39-40.

4. National Health Commission of the People's Republic of China. 2014. Available at: http://www.moh.gov.cn/ldrks/s3577/201411/ 053b067aa3c84bbd9b87bf51da0c1199.shtml. (Accessed 4 Aug 2018).

5. Ran R, Zhao C, Xu X, Yao G. Improving perfect electronic health records and integrated health information in China: a case on disease Management of Diabetes. In: Huang G, Liu X, He J, Klawonn F, Yao G, editors. Health information science. HIS 2013. Lecture notes in computer science, vol. 7798. Berlin, Heidelberg: Springer; 2013.

6. Luchenski S, et al. Survey of patient and public perceptions of electronic health Records for Healthcare, policy and research: study protocol. BMC Medical Informatics and Decision Making. 2012;12(1):40.

7. Brennana PF, Downsb S, Casper G. Project HealthDesign: rethinking the power and potential of personal health records. J Biomed Inform. 2010; 43(5):S3.

8. China, N.H.A.F.P.C.O.T.P.S.R.O. The National Basic Public Health Service Specification; 2017. p. 1.

9. Tang PC, et al. Personal health records: definitions, benefits, and strategies for overcoming barriers to adoption. J Am Med Inform Assoc. 2005:13(2):121-6.

10. Chun JR, Hong aHG. Factors affecting on personal health record. Indian Journal of Science and Technology. 2015;8(S8):173-9.

11. Agarwal $R$, et al. If we offer it, will they accept? Factors affecting patient use intentions of personal health records and secure messaging. J Med Internet Res. 2013;15(2):1-14

12. Xierali IM, et al. Factors influencing family physician adoption of electronic health records (EHRs). J Am Board Fam Med. 2013;26(4):388-93.

13. Steininger $K$, et al. Factors explaining physicians' acceptance of electronic health records. Hawaii International Conference on System Sciences. 2014:2768-77.

14. Du J, et al. Influencing factors of rural dwellers ' health record establishment in Henan province (in Chinese). Journal of Zhengzhou University: Med Sci. 2012;47(5):694-7.

15. Ren $\mathrm{H}$, Zhang J, Xiang $\mathrm{Y}$. Influence factors of demands of electronic health records among urban residents in Hangzhou (in Chinese). Chinese Journal of Preventive Medicine. 2015;16(6):434-7.

16. Rosén B. On sampling with probability proportional to size. Journal of Statistical Planning \& Inference. 1997;62(2):159-91.

17. Wang $\mathrm{H}$, et al. Health records management research of community mobile population. Journal of Community Medicine. 2014;12(10):67-9.

18. Guo X, Huang $L$. The situation and influence factors of health Records of Floating Population_-_-Based on the National Dynamic Monitoring Data of floating population survey of Sichuan Province in 2014. Population \& Development. 2016;22(3):84-90.
19. Nie H, Shen W, Bao Y. Analysis on the establishment of health records and health education status of floating population in shanghai (in Chinese). Chinese Journal of General Practice. 2016;14(1):1010-104.

20. Jiang T, Zhao Y, Shi Z. The research on Migrant's equalization of public health services quality: based on the Migrant's dynamic monitoring survey data in 2013 (in Chinese). Journal of Macro-quality Rsearch. 2015;3(1):111-9.

21. Wong DFK, Li CY, Song HX. Rural migrant Workers in Urban China: living a marginalised life. Int J Soc Welf. 2007;16:32-40.

22. Burkhard RJ, et al. Information systems and healthcare XXXVIl: when your employer provides your personal health record-exploring employee perceptions of an employer-sponsored PHR system. Commun Assoc Inf Syst. 2010;27(1):323-38.

23. Denton IC. Will patients use electronic personal health records? Responses from a real-life experience. J Healthc Inf Manag. 2001;15(3):251-9.

24. lakovidis I. Towards personal health record: current situation, obstacles and trends in implementation of electronic healthcare record in Europe. International Journal of Health Informatics. 1998;52(1):105-15.

25. Liang Z, Yu Z, Tang M, Jiang H. Determinants of the utilization of Chinese traditional health services in community health centers(in Chinese). Chinese Journal of Primary Healthcare. 2014;28(6):34-6.

26. Guo J, Wen H, Zhou Q. Status quo and determinants on basic public health services of floating population (in Chinese). Chinese Journal of Health Policy. 2014;7(8):51-6.

27. Ye H. A study on public health service use among seniors in minorities in rural China(in Chinese). Chinese Journal of Public Health Management. 2017:5:608-12.

28. Yan L, Peng Y, Zhang J, Kuang H, Tang G. Status quo of public health service use in minorities in remote Yunan(in Chinese). Chinese Rural Health Service Administration. 2017;37(1):5-7.

\section{Ready to submit your research? Choose BMC and benefit from:}

- fast, convenient online submission

- thorough peer review by experienced researchers in your field

- rapid publication on acceptance

- support for research data, including large and complex data types

- gold Open Access which fosters wider collaboration and increased citations

- maximum visibility for your research: over $100 \mathrm{M}$ website views per year

At BMC, research is always in progress.

Learn more biomedcentral.com/submissions 